\title{
Loss of the Reissner Fiber and increased URP neuropeptide signaling underlie scoliosis in a zebrafish ciliopathy mutant
}

Christine Vesque ${ }^{1 *}$, Isabelle Anselme ${ }^{1}$, Guillaume Pezeron ${ }^{2}$, Yasmine Cantaut-Belarif ${ }^{3}$, Alexis Eschstruth ${ }^{1}$, Morgane Djebar ${ }^{1}$, Diego López Santos ${ }^{1}$, Hélène Le Ribeuz ${ }^{1}$, Arnim Jenett ${ }^{4}$, Hanane Khoury ${ }^{1}$, Joëlle Véziers ${ }^{5}$, Caroline Parmentier ${ }^{6}$ and Sylvie Schneider-Maunoury ${ }^{1 *}$

1 Sorbonne Université, CNRS UMR7622, INSERM U1156, Institut de Biologie Paris Seine (IBPS) - Developmental Biology Unit, 75005, Paris, France

${ }^{2}$ Molecular Physiology and Adaptation, Muséum National d'Histoire Naturelle, CNRS UMR 7221, Paris, France

${ }^{3}$ Institut du Cerveau et de la Moelle épinière (ICM), Sorbonne Université, Inserm U 1127, CNRS UMR 7225, F-75013, Paris, France

${ }^{4}$ TEFOR Paris-Saclay, CNRS UMS2010 / INRA UMS1451, Université Paris-Saclay.

${ }^{5}$ Inserm UMR 1229, CHU Nantes PHU4 OTONN, SC3M facility, Inserm UMS 016, CNRS 3556, Université de Nantes, Nantes, France.

${ }^{6}$ Sorbonne Université, UMR8246, INSERM U1130, Institut de Biologie Paris Seine (IBPS) Neurosciences Paris Seine (NPS), 75005, Paris, France

*Co-corresponding authors. sylvie.schneider-maunoury@upmc.fr, christine.vesque@upmc.fr

\section{SUMMARY}

Cilia-driven movements of the cerebrospinal fluid (CSF) are involved in zebrafish axis straightness, both in embryos and juveniles [1, 2]. In embryos, axis straightness requires ciliadependent assembly of the Reissner fiber (RF), a SCO-spondin polymer running down the brain and spinal cord CSF-filled cavities [3]. Reduced expression levels of the urp1 and urp2 genes encoding neuropeptides of the Urotensin II family in CSF-contacting neurons (CSF-cNs) also underlie embryonic ventral curvature of several cilia motility mutants [4]. Moreover, mutants for scospondin and uts2r3 (a Urotensin II peptide family receptor gene) develop scoliosis at juvenile stages [3, 4]. However, whether RF maintenance and URP signaling are perturbed in juvenile scoliotic ciliary mutants and how these perturbations are linked to scoliosis is unknown. Here we produced mutants in the zebrafish ortholog of the human $R P G R I P 1 L$ ciliopathy gene encoding a transition zone protein [5-7]. rpgrip $1 r^{-/}$zebrafish had normal embryogenesis and developed 3D spine torsions in juveniles. Cilia lining the CNS cavities were normal in rpgrip $1 \digamma^{-}$embryos but sparse and malformed in juveniles and adults. Hindbrain ventricle dilations were present at scoliosis onset, suggesting defects in CSF flow. Immunostaining showed a secondary loss of RF correlating with juvenile scoliosis. Surprisingly, transcriptome analysis of rgprip $1 /$ mutants at scoliosis onset uncovered increased levels of urp1 and urp2 expression. Overexpressing urp2 in foxj1-expressing cells triggered scoliosis in rpgrip1/ heterozygotes. Thus, our results demonstrate that increased URP signaling drives scoliosis onset in a ciliopathy mutant. We propose that imbalanced levels of URP neuropeptides in CSF-cNs may be an initial trigger of scoliosis. 
bioRxiv preprint doi: https://doi.org/10.1101/2019.12.19.882258; this version posted December 19, 2019. The copyright holder for this preprint (which was not certified by peer review) is the author/funder, who has granted bioRxiv a license to display the preprint in perpetuity. It is made available under aCC-BY-NC-ND 4.0 International license.

KEYWORDS (up to 10): cilia, scoliosis, RPGRIP1L, zebrafish, foxj1a, urotensin II pathway, Urotensin Related Peptides, SCO-spondin, Reissner fiber, Cerebrospinal fluid. 


\section{RESULTS}

\section{Rpgrip1l zebrafish mutants develop scoliosis and show cilia defects at juvenile stage.}

To study the mechanisms of scoliosis appearance upon cilia dysfunction we made use of a zebrafish deletion mutant in the rpgrip $1 /$ gene encoding a ciliary transition zone protein (mutant generation described in Supplementary Figure S1). rpgrip $11^{\sqrt{\Delta}}$ embryos were straight and did not display any additional defects found in many ciliary mutants such as kidney cysts, randomized left-right asymmetry or retinal anomalies [8-10] (Figure 1 and Supplementary Figure S1). rpgrip $1 /^{\mathrm{s} \Delta}$ animals developed scoliosis during juvenile stages (3 weeks postfertilization (wpf) to $12 \mathrm{wpf}$ ), initiating by slight upward bending of the tail (tail-up phenotype) and progressing toward severe curvature (Figure 1A, B) with $90 \%$ penetrance in adults $(100 \%$ in females and $80 \%$ in males) (Fig.1C). Micro-computed tomography ( $\mu \mathrm{CT}$ ) at two different stages (5 wpf and 23 wpf) confirmed that spine curvature was tridimensional and initiated by a tail-up and showed no evidence of vertebral malformation or fracture (Figure 1 and Supplementary Movie 1). The Ftm/rpgrip1/ null mouse mutant displays a severe embryonic phenotype with cilia loss in the nervous system and abnormal cilia in other structures $[11,12]$. In contrast, cilia appeared normal in zebrafish rpgrip $1 /^{\mathrm{N} \Delta}$ embryos and larvae (Fig. 1G, $\mathrm{H}$ and Supplementary Figure S1), consistent with normal body axis geometry. On scanning electron microscopy (SEM) of the adult brain ventricles (Figure $1 \mathrm{I}-\mathrm{S}$ ), cilia of $r p g r i p 1 /^{\mathrm{N} \Delta}$ multiciliated brain ependymal cells were sparse and disorganized (Figure 1I, L-N) compared to controls (Figure $1 \mathrm{~J}, \mathrm{~K}$ ). In the hindbrain, cilia of monociliated ependymal cells showed abnormal, irregular structures, with bulged and thinner parts (Fig. 10-S). Cilia anomalies were already found in the spinal cord central canal (CC) at juvenile stages. Cilia were reduced in number and globally increased in length and showed strongly reduced Arl13b content (Figure $1 \mathrm{~T}-\mathrm{V}$ " and Supplementary Figure $1 \mathrm{~L}, \mathrm{M})$. Thus, rpgrip $1 /^{\mathrm{\Delta} \Delta}$ mutants show cilia defects appearing after embryogenesis and develop spine curvatures in juveniles.

\section{Rpgrip1 $^{\Delta \Delta}$ juveniles show ventricular dilations and loss of the Reissner fiber at scoliosis onset}

Ciliary beating is an essential actor of CSF flow and of ventricular development in zebrafish larvae [13]. Thus, ciliary defects in the brain of rpgrip $1 /^{N / \Delta}$ adults and juveniles could lead to abnormal ventricular volume and content. To determine whether ventricular dilations could be at the origin of scoliosis, we analyzed ventricular volume at the onset of spine curvature (Figure $2 A-G)$. Ventricular reconstruction was performed on cleared brains of 4 control and 4 rpgrip $1 /^{\Delta \Delta}$ ( 3 tail-up and 1 straight) fish at 4 wpf, stained with ZO1 to highlight the ventricular border and 
with Dil to outline brain shape, focusing on the posterior midbrain and hindbrain ventricles (Figure 2A-D). We identified a significant increase in ventricle volume in rpgrip $1 /^{N \Delta}$ fish compared to controls, restricted to ventral regions of the caudal midbrain (ROI4.4) and hindbrain (ROI6). The non-scoliotic mutant fish showed a milder dilation than the scoliotic ones (green circles in Figure 2F, G), as confirmed by sections through the hindbrain ventricle (Fig. $2 \mathrm{E}, \mathrm{G})$. In conclusion, ventricle dilations were present in the midbrain and hindbrain of rpgrip $1 /^{\Delta / \Delta}$ fish, and were more pronounced in fish at a more advanced stage of spine curvature, suggesting that these dilations could participate in scoliosis onset.

The Reissner fiber (RF) is mainly composed of SCO-spondin secreted by the subcommissural organ (SCO) and floor plate (FP) (ref). To visualize it we used an antibody that labels the RF in zebrafish embryos $[3,14]$. The RF formed normally in rgprip $11^{N \Delta}$ embryos, as expected given the absence of embryonic curvature (Supplementary Figure 1). We could visualize the RF in wild-type adult brains in SEM (Supplementary Figure 2G-J). To study its maintenance in

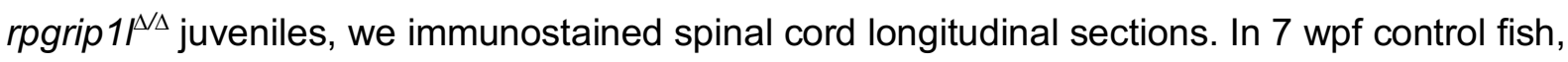
the RF was visualized as a $1 \mu \mathrm{m}$ diameter rod in the ventral part of the $\mathrm{CC}$ (Figure $2 \mathrm{H}, \mathrm{K}$, green arrowheads in Figure $2 \mathrm{H}$ ). The antibody also stained the apical cytoplasm of FP cells (Figure $2 \mathrm{H}, \mathrm{K}$, empty arrowheads in Figure $2 \mathrm{H}$ ) as well as the $\mathrm{SCO}$ in the caudal diencephalon (Figure $2 \mathrm{~N}$ ), showing that these two structures continue to produce and secrete SCO-spondin at juvenile stages. Thus, the RF is still produced and polymerized at juvenile stages, both in the brain ventricles and spinal cord CC, opening the possibility that growth and renewal of this structure beyond the larval stage could also depend on cilia integrity.

In 7 wpf rpgrip $11^{\Delta \Delta}$ fish, the RF was absent and SCO-spondin-positive debris were abundant in the central canal (Figure $2 \mathrm{I}, \mathrm{J}, \mathrm{L}, \mathrm{M}$ ). We found a RF on $96 \%$ of the sections had a RF Transverse sections at the level of the diencephalon also revealed abnormally packed material in the ventricle (Figure 2O, P). To test whether the loss of RF could drive scoliosis, we observed this structure at $3 \mathrm{wpf}$ in tail-up and straight rpgrip $1{ }^{\mathrm{N} \Delta}$ fish. All controls had a RF (found on $96 \%$ of the sections with a visible $\mathrm{CC}, 73$ sections form 5 fish analyzed). All tail-up mutants had lost the RF (small remnants found on $5 \%$ of the sections, 40 sections with CC from 2 fish), while straight mutants had a RF (found on $98 \%$ of the sections, 45 sections with CC from 3 fish) (Figure 2Q-S). Thus, in rpgrip $1 /^{\Delta / \Delta}$ fish, the loss of RF correlated with scoliosis onset.

\section{Regulators of motile ciliogenesis, embryonic axis straightness and inflammation genes are upregulated in rpgrip $1 I^{\mathrm{N} \Delta}$ juveniles}

To get further insight into the mechanisms of spine curvatures in rpgrip1/ mutants, we obtained the transcriptomes of the brain and trunk of 5 control $\left(2 \mathrm{wt}\right.$ and 3 rgprip $\left.1 /^{N^{++}}\right)$and $7 \mathrm{rpgrip} 1 /^{\mathrm{N} \Delta}$ 
juveniles (6 tail-up and 1 straight). Differential gene expression analysis was performed with one-way ANOVA. A complete annotated gene list is displayed in Supplementary Table 1. This analysis showed a large predominance of upregulated genes in the trunk (32 downregulated vs 1001 upregulated genes), and less in the brain (56 downregulated vs 235 upregulated genes) (Figure $3 \mathrm{~A}$ ). In the trunk, the most upregulated biological processes in $\mathrm{GO}$ term analysis included cilium movement, cilium assembly, cell adhesion, extracellular matrix organization and inflammation (Figure 3B). Many genes upregulated in the brain were also upregulated in the trunk, suggesting that, in the trunk, these genes were specific to the CNS (Figure $3 \mathrm{C}$ ). Among the 15 most significant GO terms, 9 were related to cilium movement or cilium assembly (not shown). This was likely due to the 5 -fold upregulation of foxj1a, encoding a master transcriptional activator of genes involved in ciliary motility [15,16] (Figure 3D). To confirm this hypothesis, we compared our dataset with those of targets of Foxj1 from [17-19]. 208 upregulated genes were targets of Foxj1, of whom 146 were direct targets (Supplementary Table 2). Another large series of genes overexpressed in mutants belonged to genes involved in inflammatory processes and immune response (Figure 3D), reminiscent of the ptk7 scoliotic mutants [20].

\section{Upregulation of URP signaling participates in scoliosis onset in rpgrip1/ mutant fish}

Several genes encoding regulators of embryonic axis curvature were also upregulated in rpgrip $1 /^{/ \Delta}$ fish, among which pkd1b [21], urp1 and upr2 [4] and scospondin [3]. urp1 and urp2 encode peptides of the Urotensin II family and are expressed in ventral spinal CSF-cNs $[22,23]$. Their downregulation underlies embryonic ventral curvature of several cilia motility mutants [4]. Thus, we wanted to confirm their overexpression and investigate its functional significance. qPCR analysis in 5 control and 5 rpgrip $1 /^{1 / \Delta}$ fish at the $3-4$ wpf stage $(0.8-0.9 \mathrm{~cm})$ confirmed urp2 overexpression in rpgrip $1 /^{\Delta / \Delta}$ fish and showed that this overexpression preceded scoliosis onset (Figure 4A). To investigate the tissue specificity of this up-regulation, we performed immunofluorescence with an antibody to a conserved domain of the Urotensin II peptide family $[24,25]$. In the zebrafish spinal cord, urp1 and urp2 are expressed in ventral CSF-cNs while other genes of the family are expressed in the caudal neurosecretory system $[23,25,26]$. Immunostaining on sagittal sections of control $(B, C)$, straight $(D, E)$ and scoliotic $(F, G)$ rpgrip $1 /^{\Delta \Delta}$ juvenile fish (3 wpf) showed that the proportion of URP-expressing cells was increased along the $\mathrm{CC}$ of straight rpgrip $1 /^{\Delta / \Delta}$ fish (Figure $4 \mathrm{H}$ ) (this could not be analyzed in scoliotic fish because the sections rarely contained a complete portion of the $\mathrm{CC}$ ). Moreover, the ratio of highly expressing CSF-cNs (full arrowheads) was significantly increased in scoliotic (but more variably in straight) rpgrip $1 /^{\Delta / \Delta}$ fish. To determine whether increased expression of URP1/2 peptides can trigger scoliosis, we injected a transgenic construct expressing urp2 in 
foxj1+ cells, lining central nervous system cavities [27], in eggs from rpgrip $11^{1 /+}$ crosses. Injected larvae displayed severe axis curvature (arrowhead) at 1-5 dpf (Figure 4J) and most of them died before 10 days. Among the survivor fish, 2/17 (12\%) rpgrip $1 /^{N^{N+}}$ heterozygotes became scoliotic whereas none of the non-injected rpgrip $1 /^{N^{+}}$heterozygotes became scoliotic (Figure 4K). This indicates that overexpression of urp2 in cells lining cavities of the central nervous system can trigger scoliosis onset in a sensitized background.

\section{DISCUSSION}

The study of juvenile scoliosis in many ciliary gene mutants is complicated by the occurrence of embryonic curvature and larval death, which requires rescuing embryonic defects to allow the mutants to reach adulthood [2]. In this paper we dissected the mechanisms of scoliosis appearance in zebrafish rpgrip1/ mutants. RPGRIP1L is a causal gene in syndromic ciliopathies and its invalidation in humans and in mice leads to severe embryonic anomalies in several organs including the brain $[5,11,12,28]$. The absence of embryonic defects of rpgrip $\left.1\right|^{\Delta \Delta}$ zebrafish, likely due to mRNA maternal stores [29] and/or to genetic compensation, makes it an excellent model to study scoliosis development.

Ventricular and CC dilations in $r p g r i p 1 /^{\Delta \Delta}$ zebrafish mutants correlated with, or just preceded, the onset of scoliosis. These dilations could be the cause of foxj1a overexpression, since foxj1a is upregulated in response to epithelial stretch in the zebrafish pronephric tubules and to tissue injury in the spinal cord [30]. The defect in RF maintenance is also a likely consequence of cilia defects and ventricle dilations. In zebrafish embryos, the RF depends on cilia for its polymerization [3]. However, the mechanisms of RF maintenance have remained elusive, mainly due to the difficulty in visualizing this structure beyond embryonic stages. Our work allows visualizing the RF in juveniles and adults and demonstrates that SCO-spondin production and RF polymerization are continuous processes. In rpgrip $1 /^{\mathrm{N} \Delta}$, the RF fails to be maintained at the onset of scoliosis. Given that SCO-spondin mutants develop spine deformities [31], the loss of the RF in rpgrip $1 /^{\mathrm{N} \Delta}$ juveniles is a likely cause of scoliosis appearance.

The knock-down of urp1 and urp2 genes in zebrafish embryos leads to a curled down axis, while their overexpression leads to the opposite curvature [4]. urp1 and urp2 are expressed in a ventral population of spinal CSF-cNs which detect spinal curvature and modulate locomotion and posture by projecting onto spinal interneurons and motoneurons [32,33]. The upregulation of $u r p 1$ and $u p r 2$ expression in rpgrip $11^{\Delta / \Delta}$ juveniles is consistent with the tail-up phenotype observed at scoliosis onset and suggests that both increased and reduced activity of this neuropeptide family in CSF-cNs can trigger scoliosis. Our finding that overexpressing urp2 
along the central canal is able to drive scoliosis in rpgrip1/ heterozygotes confirms this hypothesis.

Our results pave the way for the analysis of the interactions between RF defects, URP signaling, foxj1 overexpression and inflammation in scoliosis. Interestingly, neuroinflammation has been observed in $p t k 7^{-/}$scoliotic fish and, in this model, scoliosis is alleviated by antiinflammatory treatments [20]. Moreover, inducing focal inflammation in zebrafish leads to scoliosis [20]. How inflammation is induced in rpgrip $1 /$ mutants requires further investigation. Cilia defects can trigger inflammation in the kidney and in the brain [34,35]. Moreover, Urotensin II signaling induces inflammation in many contexts [36], raising the interesting possibility that increased URP signaling from CSF-cNs could drive neuroinflammation in the rpgrip $11^{\Delta / \Delta}$ zebrafish scoliosis model.

In conclusion, our data support the idea that an upregulation of URP signaling in CSF-CNs, downstream of defects in CSF flow and RF maintenance, underlies scoliosis onset in rpgrip 11 mutants. They allow us to propose that inappropriate levels of URP neuropeptides in these neurons, resulting in imbalanced regulation of posture or locomotion, may constitute an initial trigger of 3D spine deformities at a stage of intense body growth and tissue remodeling. This hypothesis is attractive given that loss of spine alignment is an intrinsic feature of scoliosis.

\section{ACKNOWLEDGEMENTS}

We are grateful to the IBPS aquatic animal and imaging facilities and the ICM sequencing facility for their technical assistance. We thank Michaël Trichet from the IBPS electron microscopy facility for participating in the MEB experiments, the TACGENE facility for providing the Cas9 protein; the TEFOR Paris-Saclay facility for the brain clearing experiment; Thierry Jaffredo and Pierre Charbord for their precious help in transcriptome analysis; Nicolas Baylé for initial characterization of the rpgrip1/ mutant; Claire Wyart for advice and critical reading of the manuscript. This work was supported by funding to SSM from the Fondation pour la Recherche Médicale (Equipe FRM EQU201903007943) and the Fondation Yves Cotrel.

\section{AUTHOR CONTRIBUTIONS}

Conceptualization, C.V. and S.S.M.; Methodology, C.V., I.A., A.J., G.P. and C.P.; Investigation: C.V., I.A., G.P., Y.C.B., A.E., M.D., D.L.S., H.L.R. and J.V.; Formal analysis: C.V., H.K., A.J., and S.S.M.; Validation: C.V. and S.S.M.; Writing - Original draft, C.V. and S.S.M.; Funding acquisition, S.S.M. 
bioRxiv preprint doi: https://doi.org/10.1101/2019.12.19.882258; this version posted December 19, 2019. The copyright holder for this preprint (which was not certified by peer review) is the author/funder, who has granted bioRxiv a license to display the preprint in perpetuity. It is made available under aCC-BY-NC-ND 4.0 International license.

\section{DECLARATION OF INTERESTS}

The authors declare no competing interests. 


\section{FIGURE LEGENDS}

Figure 1: rpgrip1 $^{N \Delta}$ zebrafish develop scoliosis and show cilia defects at juvenile stages.

A) Representative rpgrip $1{ }^{\Delta \Delta}$ fish at 5 days post-fertilization (dpf) (4 mm body length, larvae), $5 \mathrm{wpf}$ ( $1 \mathrm{~cm}$ body length, juveniles) and $12 \mathrm{wpf}$ ( $2.5 \mathrm{~cm}$ body length, adults), showing absence of defects in embryos, onset of spine curvature (tail up) in juveniles and scoliosis in adults. B) Graph showing the dynamics of scoliosis appearance in rpgrip $11^{1 /+}$ incrosses (total 4 clutches, 252 fish). C) Scoliosis penetrance in adults. D, E) Micro-computed tomography ( $\mu C T)$ scans of 4 control siblings (D) and 4 rpgrip $1 /^{N \Delta}(E)$ adult fish. F) Dorsal and lateral views of the superimposed spines of one control (yellow) and two rpgrip $11^{\Delta / \Delta}$ (pink, cyan) adult fish illustrating the $3 \mathrm{D}$ spine curvatures in mutants. G,H) Immunofluorescence for Acetylated tubulin in the neural tube of $2 \mathrm{dpf}$ control $(\mathrm{G})$ or rpgrip $1 /^{\Delta \Delta}(\mathrm{H})$ embryos. White vertical lines indicate the floor plate I-S) Scanning electron microscopy of the brain ventricles of control (I, $\mathrm{K}, \mathrm{O})$ and $\operatorname{rpgrip}^{1 / \Delta}(\mathrm{J}, \mathrm{L}-\mathrm{N}, \mathrm{P}-\mathrm{S})$ fish showing ciliary defects in midbrain ependymal multiciliated cells (I-N) and in hindbrain monociliated cells (O-S). Scale bars: $3 \mu \mathrm{m}$ for $\mathrm{G}, \mathrm{H}, 10$ $\mu \mathrm{m}$ for I,J; $1 \mu \mathrm{m}$ for K-S and $10 \mu \mathrm{m}$ for T-V'.

Figure 2: rpgrip1/ $^{N \Delta}$ juveniles show ventricular dilations and degeneration of the Reissner Fiber at scoliosis onset. A) Reconstruction of the posterior midbrain and hindbrain ventricles in a control transparized 5 wpf zebrafish brain stained with ZO1 antibody (ventricular surface) and Dil (global brain shape). B-D) Visualization of the ROIs shown in E. The yellow line in B indicates the level of optical sections in E. E) Optical transverse sections showing the caudal part of reconstructed ventricles of a control and two rpgrip $1 /^{\Delta \Delta}$ fish, one straight and two tail-up. F) Graphs of the ventricle volume at the onset of scoliosis in 3 control and 4 rpgrip $11^{\Delta \Delta}$ (one straight and three tail-up) fish. The dot circled in green corresponds to the straight mutant fish. G) Graph of the surface of the optical sections as illustrated in G. The dot circled in green corresponds to straight mutant fish. H-S) Visualization of the RF in sagittal sections of the trunk (H-M; Q-S) and of the brain at the level of the sub-commissural organ (SCO) (N-P) of juvenile fish, with a Sco-spondin antibody. H-P are 7 weeks post-fertilization

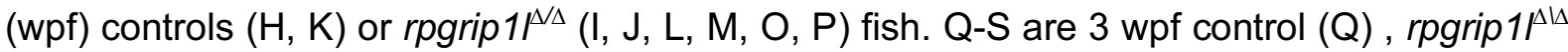
straight $(\mathrm{R})$ or curved (S). K-M are higher magnifications of the regions boxed in $\mathrm{H}-\mathrm{J}$, respectively. Green arrowheads in $\mathrm{H}, \mathrm{Q}$ and $\mathrm{R}$ and red arrowheads in $\mathrm{K}$ show the RF. Empty arrowheads in $\mathrm{K}$ show immunoreactive material in apical FP cells. At 7 weeks, the RF can be visualized in the central canal $(\mathrm{CC})$ of controls $(\mathrm{H}, \mathrm{K})$. In the dilated $\mathrm{CC}$ of rpgrip $1 /^{\mathrm{N} \Delta}$ scoliotic fish (I, J, L, M), the RF is not maintained but SCO-spondin-positive debris (white arrowheads 
in $\mathrm{L}, \mathrm{M}$ ) can be found in the CC. In the brain, SCO-spondin immunostaining is detected in controls at the apical side of SCO cells $(\mathrm{N})$. This staining is strongly reduced in mutants, but large SCO-spondin debris are found in the third ventricle $(\mathrm{V})(\mathrm{O}, \mathrm{P})$. At three wpf, controls and straight $r p g r i p 11^{\Delta \Delta}$ have a $\operatorname{RF}(Q, R)$ but the tail-up mutants have lost the $\operatorname{RF}(S)$. Scale bars: $10 \mu \mathrm{m}$ in $\mathrm{H}-\mathrm{S}$.

Figure 3: Comparative transcriptome analysis of the trunk and brain of control and

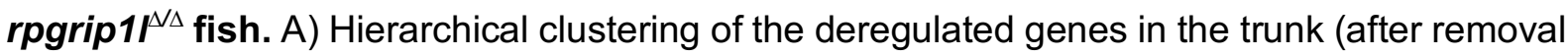
of the skin and internal organs) of $2 \mathrm{wt}, 3 \mathrm{rpgrip} 1 /^{\mathrm{N}^{+}}$and $7 \mathrm{rpgrip} 1 \mathrm{I}^{\mathrm{\Delta} \Delta}$ (6 tail-up and 1 straight) fish at $4 \mathrm{wpf}(0.9 \mathrm{~cm}$ body length). B) Go term analysis of biological processes in the trunk samples. C) Vent diagram of the upregulated genes in brain and trunk samples, based on human Refseq, showing many common genes between the two tissues. D) Selected genes of interest upregulated in the trunk and/or brain of rpgrip $1^{\Delta / \Delta}$ fish.

Figure 4: regulation of URP neuropeptide signaling underlies scoliosis onset in rpgrip1I mutants. A) qPCR confirms upregulation of urp2 expression in rpgrip $11^{\Delta \Delta}$ fish at the onset of scoliosis. Data are given in fold change compared to a control sibling chosen as standard. BI) Immunostaining on sagittal sections of control $(B, C)$, straight $r p g r i p 1 /^{N \Delta}(D, E)$ and curved $\operatorname{rpgrip} /^{\mathrm{N} \Delta}(\mathrm{F}, \mathrm{G})$ juvenile fish (3 wpf) with an antibody to the Urotensin II/URP family of neuropeptides shows that the proportion of URP1/2-expressing CSF-cNs is increased along the central canal of straight fish $(\mathrm{H})$, and the ratio of highly expressing cells (full arrowheads) is increased in scoliotic rpgrip $1 /^{\Delta / \Delta}$ fish (I). J) Injection of a transgenic construct expressing urp2 in foxj1+ cells in fertilized eggs from rpgrip $1 /^{\mathrm{N+}}$ crosses lead to axis curvatures in F0 injected fish. The construct also expressed eGFP in the heart (cmlc2 promoter) in order to assess for injection efficiency. Among injected larvae with green heart at $5 \mathrm{dpf}, 36 \%(21 / 58)$ had a straight axis (labelled straight), 24\% (14/56) had mild curvatures (mild, right images, the second from the top in a dorsal view, the others are lateral views) and $41 \%(23 / 56)$ had a severe curvature (severe, the bottom one is a dorsal view). K) Image of a scoliotic rpgrip $1 /^{N+}$ fish injected with the foxj1a::urp2 construct. Graph showing that among the survivor fish, 2/17 (12\%) became scoliotic whereas none of the non-injected rpgrip $11^{\mathrm{N+}}$ heterozygotes became scoliotic. 


\section{STAR* METHODS}

\section{EXPERIMENTAL MODEL AND SUBJECT DETAILS}

\section{Zebrafish}

Wild-type, rpgrip $\left.1\right|^{e x 4}$ and $r p g r i p 1{ }^{\wedge}$ zebrafish embryos and adults were raised, staged and maintained as previously described [37]. All our experiments were made in agreement with the european Directive 210/63/EU on the protection of animals used for scientific purposes, and the French application decree 'Décret 2013-118'. The projects of our group have been approved by our local ethical committee 'Comité d'éthique Charles Darwin'. The authorization number is 2015051912122771 v7 (APAFIS\#957). The fish facility has been approved by the French 'Service for animal protection and health' with approval number A-75-05-25. All experiments were performed on Danio rerio embryos of mixed $\mathrm{AB} / \mathrm{TL}$ background. Animals were raised at $28.5^{\circ} \mathrm{C}$ under a $14 / 10$ light/dark cycle.

\section{CONTACT FOR REAGENT AND RESOURCE SHARING}

Sylvie Schneider-Maunoury

sylvie.schneider-maunoury@upmc.fr

Christine Vesque

Christine.vesque@upmc.fr

\section{KEY RESOURCES TABLE}

Provided separately

\section{METHOD DETAILS}

\section{Rpgrip1l mutant generation and genotyping}

\section{Guide RNA preparation and microinjection}

Crispr target sites were selected for their high predicted specificity and efficiency using the CRISPOR online tool [38]. Real efficiency was assessed on zebrafish embryos by T7E1 test [39]. The two most efficient guides (Rpgrip1I_x4_G1: GCTTACGGTCCTTCACCAGACGG and Rpgrip1I_x25_G3: CCTCAGTTGACAGGTTTCAGCGG) respectively situated $24 \mathrm{nt}$ from beginning of exon 4 and $82 \mathrm{nt}$ downstream of exon 25 were kept for further experiments.

sgRNA transcription templates were obtained by PCR using T7_Rpgrip1l-x4_G1_Fw primer (5'GAAATTAATACGACTCACTATAGGCTTACGGTCCTTCACCAGAGTTTTAGAGCTAGAAATAGC$\left.3^{\prime}\right)$ or T7_Rpgrip1I-x25_G3_Fw 


\section{GAAATTAATACGACTCACTATAGGCCTCAGTTGACAGGTTTCAGGTTTTAGAGCTAGAAATAG}

C-3') as forward primer and sgRNA_R universal primer (5'AAAAGCACCGACTCGGTGCCACTTTTTCAAGTTGATAACGGACTAGCCTTATTTTAACTTGCTA TTTCTAGCTCTAAAAC-3') as reverse primer. sgRNAs were transcribed using Megascript T7 Transcription Kit (Thermo Fisher Scientific, Waltham, MA) and purified using NucleoSpin® RNA Clean up XS kit (Macherey Nagel, Düren, Germany). sgRNA:Cas9 RNP complex was obtain by incubating Cas9 protein (gift of TACGENE, Paris, France) $(7.5 \mu \mathrm{M})$ with sgRNA $(10 \mu \mathrm{M})$ in $20 \mathrm{mM}$ Hepes- $\mathrm{NaOH} \mathrm{pH} \mathrm{7.5,} 150 \mathrm{mM} \mathrm{KCl}$ for $10 \mathrm{~min}$ at $28^{\circ} \mathrm{C}$. 1-2 $\mathrm{nl}$ was injected per embryo. For deletion, Rpgrip1I_x4_G1 and Rpgrip1I_x25_G3 RNP complexes were mixed half and half.

\section{Screening and genotyping}

Injected (F0) fish were screened for germline transmission by crossing with wild type fish and extracting genomic DNA from obtained embryos. For genomic DNA extraction, caudal fin (juveniles/adults) or whole embryo DNA were used. Genomic DNA was isolated with Proteinase K (PK) digestion in 40 of lysis buffer (100 mM Tris- $\mathrm{HCl} \mathrm{pH}$ 7.5, $1 \mathrm{mM}$ EDTA, $250 \mathrm{mM} \mathrm{NaCl}, 0.2 \%$ SDS, $0.1 \mu \mathrm{g} / \mu \mathrm{l}$ Proteinase $\mathrm{K})$ for embryos $\left(300 \mu \mathrm{l}\right.$ for adult fin) overnight at $37^{\circ} \mathrm{C}$ with agitation. PK enzyme was inactivated $10 \mathrm{~min}$ at $90^{\circ} \mathrm{C}$ and a five fold dilution was used as a template for PCR amplification. Genotyping of mutations in exon 4 and deletion between the two Crispr target sites was performed by PCR using Rpgrip1I_x4_F (TTGTGACACCGCATGCATTT) as forward primers and Rpgrip1I_x4_R4 (CCGTGAGGTGGTCACCGG) as reverse primers for mutations and Rpgrip1I-x25R (ACATCAGAGGAAATCTTCTTTATTCAGC) as reverse primers for deletion.

\section{$\mu \mathrm{CT}$ scans}

The samples were scanned on a Bruker micro scanner (Skyscan 1272) with a resolution of $8.5 \mu \mathrm{m}$, a rotation step of $0.55^{\circ}$ and a total rotation of $180^{\circ}$. For the acquisition of adult fish $(2,5 \mathrm{~cm})$, a 0.25 $\mathrm{mm}$ aluminium filter was used, for a voltage of $50 \mathrm{kV}$ and an intensity of $180 \mathrm{~mA}$, for juveniles fish $(0,9$ to $1,2 \mathrm{~cm})$ the filter was omitted, and a voltage of $60 \mathrm{kV}$ was used with an intensity of $166 \mathrm{~mA}$. Each image contained $1008 \times 672$ pixels and was based on the average of 3 images. The 3D reconstruction by backprojection was carried out by the NRecon software and the 2D image overlays were then cleaned by the CT Analyser software. The Dataviewer software allowed all fish skeletons to be oriented in the same way taking the otoliths as landmarks. The CTvox software then allowed $3 \mathrm{D}$ visualizing of the samples. Morphometric analysis was performed with the CT Analyser software.

\section{Scanning electron microscopy}

Fish were euthanized using lethal concentration of MS222 $(0.028 \mathrm{mg} / \mathrm{mL})$. The brains were quickly dissected in $1.22 \times$ PBS $(\mathrm{pH} 7.4), 0.1 \mathrm{M}$ sodium cacodylate and fixed overnight with $2 \%$ glutaraldehyde in $0.61 \mathrm{XPBS}(\mathrm{pH} 7.4), 0.1 \mathrm{M}$ sodium cacodylate at $4^{\circ} \mathrm{C}$. They were sectioned along the dorsal midline with a razor blade to expose their ventricular surfaces. Both halves were washed 
four times in 1.22 X PBS and post-fixed for 15 minutes in $1.22 \times$ PBS containing $1 \%$ OsO4. Fixed samples were washed four times in ultrapure water, dehydrated with a graded series of ethanol and critical point dried (CPD 300, Leica) at 79 bar and $38^{\circ} \mathrm{C}$ with liquid CO2 as the transition fluid and then depressurized slowly $(0,025 \mathrm{bar} / \mathrm{s})$. They were then mounted on aluminum mounts with conductive silver cement. Sample surfaces were coated with a $5 \mathrm{~nm}$ platinum layer using a sputtering device (ACE 600, Leica). Samples were observed under high vacuum conditions using a Field Emission Scanning Electron Microscope (Gemini 500, Zeiss) operating at $5 \mathrm{kV}$, with a $20 \mu \mathrm{m}$ objective aperture diameter and a working distance around $3 \mathrm{~mm}$. Secondary electrons were collected with an in-lens detector. Scan speed and line compensation integrations were adjusted during observation.

\section{Histological sections of juvenile and immunofluorescence on sections}

Juvenile and adult zebrafish were euthanized using lethal concentration of MS222 $(0.028 \mathrm{mg} / \mathrm{mL})$. Pictures and size measurements were systematically taken before fixation. Fish were fixed in Zamboni fixative [35 ml PFA $4 \%, 7.5 \mathrm{ml}$ saturated picric acid $(1.2 \%), 7.5 \mathrm{ml} \mathrm{0.2M} \mathrm{Phosphate} \mathrm{Buffer}$ (PB)] [40] overnight at $4^{\circ} \mathrm{C}$ under agitation. Fish were washed with Ethanol $70 \%$ and processed for dehydration by successive $1 \mathrm{~h}$ incubation in Ethanol $(3 \times 70 \%$ and $2 \times 100 \%)$ and Butanol $(2 \times 100 \%)$ at room $\mathrm{T}^{\circ}$ under agitation, then for paraffin inclusion. $14 \mu \mathrm{m}$ sagittal paraffine sections were obtained using a Leica RM2125RT microtome. Sections were deparaffinized and antigen retrieval was performed by incubation for $7 \mathrm{~min}$ in boiling citrate buffer $(10 \mathrm{mM}, \mathrm{pH} 6)$. Immunofluorescence staining was performed as described previously [41]. The following primary antibodies were used: anti-RF, anti-Urotensin II, anti-Acetylated Tubulin, anti-Glutamylated Tubulin, anti-Arl13b. Corresponding primary and secondary antibodies are described and referenced in the Key

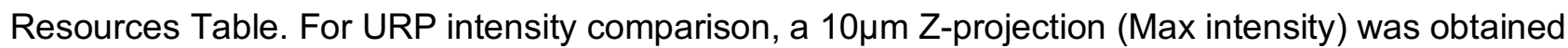
for each field and graded pixel intensities were visualized using the FIRE tool in FIJI software. Three classes of intensities were defined: "weak" corresponds to blue color and partial cytoplasm staining, "medium" corresponds to pink color and uniform cytoplasmic staining, "strong" corresponds to yellow color and staining of both cytoplasm and axon. Ventral CSF-cN density corresponds to the ratio of URP-positive cells over the number of DAPI stained nuclei lining the CC ventrally.

\section{Immunofluorescence on whole embryos}

Embryos from 24 to $40 \mathrm{hpf}$ were fixed $4 \mathrm{hr}$ to overnight in $4 \%$ paraformaldehyde (PFA) at $4^{\circ} \mathrm{C}$. Larvae at 48 and $72 \mathrm{hpf}$ were fixed $2 \mathrm{hr}$ in $4 \%$ PFA and $3 \%$ sucrose at $4^{\circ} \mathrm{C}$, skin from the rostral trunk was partially removed and yolk was removed. Samples from 24 to $40 \mathrm{hpf}$ embryos were blocked overnight in a solution containing $0.5 \%$ Triton, $1 \%$ DMSO, $10 \%$ normal goat serum and $2 \mathrm{mg} / \mathrm{mL}$ BSA. Samples from 48 to $72 \mathrm{hpf}$ larvae were blocked in $0.7 \%$ Triton, $1 \%$ DMSO, 10\% NGS and $2 \mathrm{mg} / \mathrm{mL}$ BSA. Primary antibodies were incubated one to two nights at $4^{\circ} \mathrm{C}$ in a buffer containing $0.5 \%$ Triton, 
$1 \%$ DMSO, 1\% NGS and $1 \mathrm{mg} / \mathrm{mL}$ BSA. All secondary antibodies were from Molecular Probes, used at 1:400 in blocking buffer, and incubated $2.5 \mathrm{hr}$ at room temperature. The following primary antibodies were used for in toto immunohistochemistry with anti-Reissner fiber and anti-Acetylatedtubulin antibodies. Corresponding primary and secondary antibodies are described and referenced in the Key Resources Table. Whole mount zebrafish embryos (dorsal or lateral mounting in Vectashield Mounting Medium) were imaged on an Leica SP5 confocal microscope equipped with a $63 \mathrm{X}$ immersion objective. Images were then processed using Fiji.

\section{Whole-mount brain clearing}

Brains were dissected from 4-5 wpf size-matched (0.9-1.2 mm length) zebrafish after in toto fixation with formaldehyde. Whole-mount tissue clearing was performed following the zPACT protocol [42]. In brief, brains were infused for 2 days in hydrogel monomer solution ( $4 \%$ acrylamide, $0.25 \%$ VA$044,1 \%$ formaldehyde and $5 \%$ DMSO in $1 \mathrm{X} \mathrm{PBS}$ ) at $4^{\circ} \mathrm{C}$. Polymerization was carried out for $2 \mathrm{~h} 30$ at $37^{\circ} \mathrm{C}$ in a desiccation chamber filled with pure nitrogen. Brains were transferred into histology cassettes and incubated in clearing solution ( $8 \%$ SDS and $200 \mathrm{mM}$ boric acid in $\mathrm{dH} 2 \mathrm{O}$ ) at $37^{\circ} \mathrm{C}$ with gentle agitation for 8 days. Cleared brains were washed in 1X PBS with $0.1 \%$ Tween-20 (PBT) for 3 days at room temperature and kept in $0.5 \%$ formaldehyde, $0.05 \%$ sodium azide in PBT at $4^{\circ} \mathrm{C}$ until further processing. Brains were subsequently placed for $1 \mathrm{~h}$ in depigmentation pre-incubation solution ( $0.5 \mathrm{XSSC}, 0.1 \%$ Tween-20 in $\mathrm{dH} 2 \mathrm{O}$ ) at room temperature. The solution was replaced by depigmentation solution (0.5X SSC, Triton X-100 0.5\%, formamide $0.05 \%$ and $\mathrm{H} 2 \mathrm{O} 20.03 \%$ in $\mathrm{dH} 2 \mathrm{O}$ ) for 45 minutes at room temperature. Depigmented brains were washed for $4 \mathrm{~h}$ in PBT and post-fixed ( $2 \%$ formaldehyde and $2 \%$ DMSO in PBT) overnight at $4{ }^{\circ} \mathrm{C}$.

\section{Cleared brain immunostaining}

Whole-mount immunolabeling of cleared brains was performed as described in the zPACT protocol with slight modifications. Briefly, brains were washed in PBT for one day at room temperature and blocked for $10 \mathrm{~h}$ in 10\% normal goat serum, 10\% DMSO, 5\% PBS-glycine $1 \mathrm{M}$ and $0.5 \%$ Triton X-100 in PBT at room temperature. Brains were washed again in PBT for $1 \mathrm{~h}$ prior to incubation with antiZO-1 antibody (ZO1-1A12, Thermofisher, 1:150) in staining solution (2\% normal goat serum, $10 \%$ DMSO, $0.1 \%$ Tween-20, $0.1 \%$ Triton X-100 and $0.05 \%$ sodium azide in PBT) for 12 days at room temperature under gentle agitation. Primary antibody was renewed once after 6 days of incubation. Samples were washed three times in PBT and thereafter incubated with Alexa Fluor 488-conjugated secondary antibody (A11001, Invitrogen, 1:200) for 10 days in staining solution at room temperature under gentle agitation. Secondary antibody was renewed once after 5 days of incubation. Samples were washed three times in PBT prior to a counterstaining with DilC18 (D282, Invitrogen, $1 \mu \mathrm{M})$ in staining solution for three days at room temperature with gentle agitation. Samples were washed in PBT for $3 \mathrm{~h}$ before mounting procedure. 


\section{Mounting and confocal imaging}

Samples were placed in 50\% fructose-based high-refractive index solution (fbHRI, see [42]) $/ 50 \%$ PBT for $1 \mathrm{~h}$, then in $100 \%$ fbHRI. Brains were mounted in agarose-coated $(1 \%$ in standard embryo medium) $60 \mathrm{~mm}$ Petri dish with custom imprinted niches to help orientation. Niche-fitted brains were embedded in $1 \%$ phytagel and the Petri dish filled with $100 \% \mathrm{fbHRI}$. fbHRI was changed three times before imaging until its refractive index matched 1.457. Images were acquired with a Leica TCS SP8 laser scanning confocal microscope equipped with a Leica HC FLUOTAR L 25x/1.00 IMM motCorr objective. Brains were scanned at a resolution of $1.74 \times 1.74 \times 1.74 \mu \mathrm{m}(\mathrm{xyz})$ and tiled into 45 to 70 individual image stacks, depending on brain dimensions, subsequently stitched, using LAS $X$ software.

\section{Volumetric analysis of the posterior ventricles}

The volumes of the posterior ventricles were segmented, reconstructed and analyzed using Amira for Life \& Biomedical Sciences software (Thermo Fisher Scientific). In essence the ventricles volumes were manually segmented in Amira's segmentation editor and subsequently refined by local thresholding and simplification of the corresponding surfaces. Volumes, which were open to the environment were artificially closed with minimal surfaces by connecting the distal-most points of their surface to the contralaterally corresponding points using straight edges. Due to the biologic variability of the sample population the overall size of the specimens needed to be normalized to keep the measured volumes comparable. For this spatial normalization one of the specimens was randomly selected from the wildtype population as template (1664, grey) and the 'Registration' module in Amira was used to compute region-specific rigid registrations for the other specimens, allowing for isotropic scaling only [details in supp. mat.]. For excluding the influence of the ventricular volumes, the registration was computed on the basis of the independent reference stain (DilC18) (details in supp. mat.). Region specific volume differences between the mutant and wildtype population were evaluated on seven subvolumes of the posterior ventricles (details in supp. mat.).

\section{RNA extraction for transcriptome analysis and quantitative RT-PCR.}

Juvenile and adult zebrafish were euthanized using lethal concentration of MS222 $(0.28 \mathrm{mg} / \mathrm{mL})$. Their length was measured and their fin cut-off for genotyping. For transcriptomic analysis, brain and dorsal trunk from 1 month juvenile $(0,9$ to $1,0 \mathrm{~cm})$ zebrafish were dissected in cold PBS with forceps and lysed in QIAzol (QIAGEN) after homogenization with plunger pistons and $1 \mathrm{ml}$ syringes. Samples were either stored in QIAzol at $-80^{\circ} \mathrm{C}$ or immediately processed. Extracts containing RNA were loaded onto QIAGEN-mini columns, DNAse digested and purified in the miRNAeasy QIAGEN kit (Cat 217004) protocol. Samples were stored at $-80^{\circ} \mathrm{C}$ until use. RNA concentration and size profile were obtained on the Tapestation of ICM platform. All preparations had a RIN above 9.2. For Q-PCR 
from 3 weeks juveniles, whole fish minus internal organs were lysed in Trizol (Life technologies) using the Manufacturer protocole.

\section{Quantitative PCR}

The cDNA from the isolated RNAs was obtained following GoScript Reverse Transcription System protocol (Promega), using $4 \mu \mathrm{g}$ of total RNA for each sample. The $20 \mu \mathrm{L}$ RT-reaction was diluted 4 fold and $4 \mu \mathrm{l}$ was used for each amplification performed in duplicates. The primers used for qPCR were the following: urp2 (F: AGAGGAAACAGCAATGGACG; R: TGTTGGTTTTCTTGGTTGACG) [Zhang X et al., 2018], rpgrip1l (F: CAGACACCTGCTGGAGTTACA; R:

TCCTGACTCACATCAAACGCA), mob4 (F: CACCCGTTTCGTGATGAAGTACAA; R: GTTAAGCAGGATTTACAATGGAG) or Ism12b F GAGACTCCTCCTCCTCTAGCAT and R GATTGCATAGGCTTGGGACAAC. The Q-PCR were performed using the StepOne real-time PCR system and following its standard amplification protocol (Thermo Scientific). Relative gene expression levels were quantified using the comparative CT method (2- $\Delta \Delta C T$ method) on the basis of $C T$ values for target genes and either mob4 or Ism12b as internal controls.

\section{RNA-sequencing and analysis}

RNA-seq libraries were constructed at ICM according to standard Illumina protocols and sequenced on an Illumina NovaSeq 6000 to obtain about 40 megabases of sequence in total, both strands. Paired-end reads were aligned against the GRCz11 genome using the STAR RNA-seq aligner with default parameters outputting FastQ files using Partekflow ${ }^{\mathrm{TM}}$. Gene-expression levels in terms of transcripts per million were estimated by HTseq-count, and differentially expressed gene (DEG) analysis was carried out using ANOVA. The genes with a fold-change value of 2 or more and an adjusted $p$ value of less than 0.01 were defined as significant DEGs. The list of differentially expressed genes was then generated. Gene Ontology GO analysis was performed using DAVID (https://david.ncifcrf.gov/). Principle component Analysis PCA and Hierarchical clustering were performed using Partek genomics suite ${ }^{\mathrm{TM}}$.

\section{Generation and injection of the foxj1a::upr2 construct}

To generate the foxj1a::urp2 construct, the urp2 ORF was amplified from 24hpf zebrafish cDNA (URP2_BamHI_F: gcgcgcGGATCCgtatctgtagaatctgcttgctgc, URP2_Xbal_R: gcgcgcTCTAGAggcagagggtcagtcgtgttat) and cloned into pME-MCS (tol2kit, [45]). The final transgene was then obtained by LR recombination (using the Gateway vector construction kit (Life Technologies)) with the entry plasmids p5E-fox1a (containing foxj1a regulatory sequences [2]. pMEurp2 and p3E-polyA into pDestTol2CG2 the destination vector (tol2kit). The vector contains and an additional cassette consisting of EGFP expressed under the control of $\mathrm{cm} / \mathrm{c} 2$ promoter which allows visualizing GFP+ hearts from $1 \mathrm{dpf}$ in injected embryos expressing the transgene. A volume of $1 \mathrm{nl}$ of a mix containing the circular plasmid at 10-15 $\mathrm{ng} / \mu \mathrm{l}$ together with Tol2 transposase mRNA at 
$20 \mathrm{ng} / \mu \mathrm{l}$ was injected at the 1 cell-stage or at the 2-4 cell-stage embryos from $r$ prip $11^{N^{++}} \mathrm{x}$ wt outcrosses. The proportion of very malformed embryos at $24 \mathrm{hpf}$ (reduced head, short and highly twisted body) was high when injected at the 1 cell-stage ( $77 \%$ death before $5 \mathrm{dpf}, 37 / 48$ embryos) and lower when injected at the 2-4 cell-stage (27\% death before $5 \mathrm{dpf}, \mathrm{n}=77 / 106$ embryos). At $5 \mathrm{dpf}$, injected larvae that had properly inserted the transgene were selected based on green fluorescence in the heart. Injected larvae and non-injected control siblings were raised to adulthood for genotyping and scoliosis scoring.

\section{QUANTIFICATION AND STATISTICAL ANALYSIS}

For all experiments the number of samples analyzed is indicated in the text and/or visible in the figures (scatter plots). Because the number of samples was generally too low to achieve normality of distribution (except in Supplementary Figure 1), a non-parametric Mann-Whitney test was performed for all quantifications. For cilia length and density in Supplementary Figure 1, both parametric (unpaired $T$ test) and non-parametric (Mann-Whitney test) were performed and gave similar results. Statistical analysis was performed using the Prism software. ${ }^{* * *}$ : $P$ value $<0.0001$; ${ }^{* * *}$ : $P$ value $<0.001 ;{ }^{* *}: P$ value $<0.01 ;{ }^{*}: P$ value $<0.05$ 


\section{SUPPLEMENTARY MATERIAL}

\section{Supplementary Figure 1: Production and characterization of the $\left.r p g r i p 1\right|^{e x 4}$ and

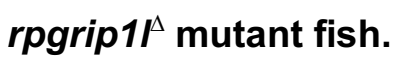

A) Graph showing the exon-intron structure of the Danio rerio rpgrip1/gene. Two alleles were produced by CRISPR/cas9-mediated genome engineering, rpgrip $11^{e x 4}$ with a nonsense mutation in exon 4 and rpgrip $11^{\wedge}$ with a large deletion encompassing most of the protein coding sequence. Both alleles had identical phenotype (panel D and data not shown). Only rpgrip $11^{\Lambda}$ was further studied. B, C) Absence of muscle pioneer defects. In rpgrip $11^{\Delta / \Delta}$ as in control (ctl) $24 \mathrm{hpf}$ larvae, a normal distribution of muscle pioneer cells expressing both Engrailed (green) and Prox1 (magenta) is observed, and a characteristic chevron shape of the somites (Prox1+, Engrailed-fast muscle cells) is present in rpgrip $1 /^{\wedge \Delta}$ embryos (C) as in controls (B), indicating normal $\mathrm{Hh}$ signaling. D) Absence of laterality defects and of kidney cysts in rpgrip $\left.1\right|^{\mathrm{N} \Delta}$ and rpgrip $1 /^{\text {ex/ex4 }}$ embryos. E-G) Absence of retinal defects and normal photoreceptor cilia in $5 \mathrm{dpf}$ rpgrip $1 /^{N \Delta}$ larvae. Retinal sections of control $(E)$ and $r p g r i p 1 I^{/ \Delta}(F)$ were immunostained with Zpr3 (red, to label the external segment of photoreceptors) and Acetylated Tubulin (Ac Tub, green) to label cilia. Insets in $E$ and $F$ focus on the photoreceptor cilia. G) Graph of photoreceptor cilia length. Cilia are slightly longer in rpgrip $1 /^{N \Delta}(n=101$ cilia) than in control $(n=131$ cilia) retinas. $H-K)$ Cilia of olfactory sensory neurons $(H, I)$ and of neuromast hair cells $(\mathrm{J}, \mathrm{K})$ appear similar in control $(\mathrm{H}, \mathrm{J})$ and $\operatorname{rpgrip} /^{\mathrm{N} \Delta}(\mathrm{I}, \mathrm{K}) 5 \mathrm{dpf}$ larvae. $\left.\mathrm{L}\right) \mathrm{Graph}$ of cilia density in the CC of juvenile control (12 ROIs of 2 animals) and rpgrip $11^{\Delta / \Delta}$ (26 ROIs of 2 animals) fish. Density is the number of cilia per $100 \mu \mathrm{m} \mathrm{CC} \mathrm{length.} \mathrm{Although} \mathrm{the} \mathrm{cilia} \mathrm{density} \mathrm{varies} \mathrm{along}$ the length of the $\mathrm{CC}$, it is statistically lower in rpgrip $1 /^{\mathrm{N} \Delta}$ juvenile fish $\mathrm{CC}$ than in control CC. M) Graph of cilia length (in $\mu \mathrm{m}$ ) in the dorsal and ventral CC of control ( $n=135$ cilia of 2 fish) and rpgrip $1 /^{/ \Delta}\left(\mathrm{n}=199\right.$ cilia of 2 fish) rpgrip $1 /^{\nu_{\Delta}}$ juvenile fish. Cilia are longer in $\left.r p g r i p 1\right|^{\Delta \Delta,}$ particularly in the dorsal CC. Scale bars: $20 \mu \mathrm{m}$ in B, C; $50 \mu \mathrm{m}$ in $\mathrm{E}, \mathrm{F} ; 25 \mu \mathrm{m}$ in $\mathrm{H}, \mathrm{I}$ and $10 \mu \mathrm{m}$ in J, K.

\section{Supplementary Figure 2. Visualization of the RF in embryos and adults.}

A-F) Immunofluorescence on whole $30 \mathrm{hpf}$ control (A, C, E) and rpgrip $1 /^{\mathrm{N} \Delta}(\mathrm{B}, \mathrm{D}, \mathrm{F})$ embryos to visualize the RF (anti-RF antibody) and cilia (Acetylated Tubulin Antibody). Nuclei are stained with DAPI. The RF is present and of normal appearance in the central canal of rpgrip $1 /^{N \Delta}$ embryos. G-J) SEM on wt adult brain to visualize the RF in brain ventricles. Scale bars: $10 \mu \mathrm{m}$ in A-F, $2 \mu \mathrm{m}$ in $\mathrm{G}, 10 \mu \mathrm{m}$ in $\mathrm{H}, 1 \mu \mathrm{m}$ in I and $400 \mathrm{~nm}$ in $\mathrm{J}$. 


\section{Supplementary Movie 1. $\mu \mathrm{CT}$ in juveniles.}

Superposition of 3D-reconstructed spines of 5 wpf juvenile fish, 1 control (white), 3 rpgrip $11^{/ \Delta}$ of different severities: 2 tail-up (yellow, blue) and 1 scoliotic (pink).

\section{Supplementary Movie 2. Ventricle reconstruction: whole brain view.}

\section{Supplementary Table 1. Excel file with a list of genes deregulated in rpgrip1 ${ }^{\Delta \Delta}$.}

Sheet 1: Trunk transcriptome, list of genes upregulated in rpgrip $1 /^{N \Delta}$ samples compared to controls. Sheet 2: Trunk transcriptome, list of genes downregulated in rpgrip $\left.1\right|^{\Delta / \Delta}$ samples compared to controls. Sheet 3: Brain transcriptome, list of genes upregulated in rpgrip $\left.1\right|^{\Delta \Delta}$ samples compared to controls. Sheet 4: Brain transcriptome, list of genes downregulated in rpgrip $1 /^{1 / \Delta}$ samples compared to controls. Data were filtered with $p$ values $<0.01$ for transcripts regarded as statistically significant and fold changes $f \geq 2$. In column 5 (Refseq protein), Refseq is given for the human orthologue when available.

\section{Supplementary Table 2 List of Foxj1a target genes upregulated in the trunk of rpgrip1/ ${ }^{\Delta \Delta}$} juvenile fish. The gene list was compared to Foxj1 target genes identified in [17-19]. Colour code: Yellow indicates that the target gene was found in [17] or [18] and in [19]; green indicates that the gene was found in [17] or [18] but not in [19]; orange indicates that it was found in [19] only.

\section{Supplementary Methods}




\section{REFERENCES}

[1] Boswell, C.W., and Ciruna, B. (2017). Understanding Idiopathic Scoliosis: A New Zebrafish School of Thought. Trends Genet. 33, 183-196.

[2] Grimes, D.T., Boswell, C.W., Morante, N.F., Henkelman, R.M., Burdine, R.D., and Ciruna, B. (2016). Zebrafish models of idiopathic scoliosis link cerebrospinal fluid flow defects to spine curvature. Science 352, 1341-4.

[3] Cantaut-Belarif, Y., Sternberg, J.R., Thouvenin, O., Wyart, C., and Bardet, P.L. (2018). The Reissner Fiber in the Cerebrospinal Fluid Controls Morphogenesis of the Body Axis. Curr. Biol. 28, 2479-2486.

[4] Zhang, X., Jia, S., Chen, Z., Chong, Y.L., Xie, H., Feng, D., Wu, X., Song, D.Z., Roy, S., and Zhao, C. (2018). Cilia-driven cerebrospinal fluid flow directs expression of urotensin neuropeptides to straighten the vertebrate body axis. Nat. Genet. 50, 1666-1673.

[5] Delous, M., Baala, L., Salomon, R., Laclef, C., Vierkotten, J., Tory, K., Golzio, C., Lacoste, T., Besse, L., Ozilou, C., et al. (2007). The ciliary gene RPGRIP1L is mutated in cerebello-oculo-renal syndrome (Joubert syndrome type B) and Meckel syndrome. Nat. Genet. 39, 875-81.

[6] Shi, X., Garcia III, G., Van DeWeghe, J.C., McGorty, R., Pazour, G.J., Doherty, D., Huang, B., and Reiter, J.F. (2017). Super-resolution microscopy reveals that disruption of ciliary transition-zone architecture causes Joubert syndrome. Nat. Cell. Biol. 19, 1178-1191.

[7] Wiegering, A., Dildrop, R., Kalfhues, L., Spychala, A., Kuschel, S., Lier, J.M., Zobel, T., Dahmen, S., Leu, T., Struchtrup, A., Legendre, F., Vesque, C., Schneider-Maunoury, S., Saunier, S., Rüther, U., and Gerhardt, C. (2018). Cell type-specific regulation of ciliary transition zone assembly in vertebrates. EMBO J. e97791.

[8] Tsujikawa, M., and Malicki, J. (2004). Intraflagellar transport genes are essential for differentiation and survival of vertebrate sensory neurons. Neuron. 42, 703-16.

[9] Kramer-Zucker, A.G., Olale, F., Haycraft, C.J., Yoder, B.K., Schier, A.F., and Drummond, I.A. (2005). Cilia-driven fluid flow in the zebrafish pronephros, brain and Kupffer's vesicle is required for normal organogenesis. Development 132, 1907-21.

[10] Bachmann-Gagescu, R., Phelps, I.G., Stearns, G., Link, B.A., Brockerhoff, S.E., Moens, C.B., and Doherty, D. (2011). The ciliopathy gene cc2d2a controls zebrafish photoreceptor outer segment development through a role in Rab8-dependent vesicle trafficking. Hum. Mol. Genet. 20, 4041-55.

[11] Besse, L., Neti, M., Anselme, I., Gerhardt, C., Rüther, U., Laclef, C., and SchneiderMaunoury, S. (2011). Primary cilia control telencephalic patterning and morphogenesis via Gli3 proteolytic processing. Development. 138, 2079-88.

[12] Andreu-Cervera, A., Anselme, I., Karam, A., Laclef, C., Catala, M., and SchneiderMaunoury, S. (2019). The Ciliopathy Gene Ftm/Rpgrip1I Controls Mouse Forebrain Patterning via Region-Specific Modulation of Hedgehog/Gli Signaling. J. Neurosci. 39, 2398-2415.

[13] Olstad, E.W., Ringers, C., Hansen, J.N., Wens, A., Brandt, C., Wachten, D., Yaksi, E., and Jurisch-Yaksi, N. (2019). Ciliary Beating Compartmentalizes Cerebrospinal Fluid Flow in the Brain and Regulates Ventricular Development. Curr. Biol. 29, 229-241.e6.

[14] Didier, R., Dastugue, B., and Meiniel, A. (1995). The secretory material of the subcommissural organ of the chick embryo. Characterization of a specific polypeptide by two-dimensional electrophoresis. Int. J. Dev. Biol. 39, 493-499.

[15] Yu, X., Ng, C.P., Habacher, H., and Roy, S. (2008). Foxj1 transcription factors are master regulators of the motile ciliogenic program. Nat. Genet. 40, 1445-53. 
[16] Wallmeier, J., Frank, D., Shoemark, A., Nöthe-Menchen, T., Cindric, S., Olbrich, H., Loges, N.T., Aprea, I., Dougherty, G.W., Pennekamp, P., et al. (2019). De Novo Mutations in FOXJ1 Result in a Motile Ciliopathy with Hydrocephalus and Randomization of Left/Right Body Asymmetry. Am. J. Hum. Genet. 105, 1030-1039.

[17] Choksi, S.P., Babu, D., Lau, D., Yu, X., and Roy, S. (2014). Systematic discovery of novel ciliary genes through functional genomics in the zebrafish. Development 141, 3410-9.

[18] Quigley, I.K., and Kintner, C. (2017). Rfx2 Stabilizes Foxj1 Binding at Chromatin Loops to Enable Multiciliated Cell Gene Expression. PLoS Genet. 13, e1006538.

[19] Mukherjee, I., Roy, S., and Chakrabarti, S. (2019). Identification of Important Effector Proteins in the FOXJ1 Transcriptional Network Associated With Ciliogenesis and Ciliary Function. Front. Genet. 10, 23.

[20] Van Gennip, J.L.M., Boswell, C.W., and Ciruna, B. (2018). Neuroinflammatory signals drive spinal curve formation in zebrafish models of idiopathic scoliosis. Sci Adv. 4, eaav1781.

[21] Mangos, S., Lam, P.Y., Zhao, A., Liu, Y., Mudumana, S., Vasilyev, A., Liu, A., and Drummond, I.A. (2010). The ADPKD genes pkd1a/b and pkd2 regulate extracellular matrix formation. Dis. Model Mech. 3, 354-65.

[22] Parmentier, C., Hameury, E., Dubessy, C., Quan, F.B., Habert, D., Calas, A., Vaudry, H., Lihrmann, I, and Tostivint, H. (2011). Occurrence of two distinct urotensin ii-related peptides in zebrafish provides new insight into the evolutionary history of the urotensin ii gene family. Endocrinology, 152, 2330-41.

[23] Quan, F.B., Dubessy, C., Galant, S., Kenigfest, N.B., Djenoune, L., Leprince, J., Wyart, C., Lihrmann, I., and Tostivint, H. (2015). Comparative distribution and in vitro activities of the urotensin II-related peptides URP1 and URP2 in zebrafish: evidence for their colocalization in spinal cerebrospinal fluid-contacting neurons. PLoS One 10, e0119290.

[24] Winter, M.J., Hubbard, P.C., McCrohan, C.R., and Balment, R.J. (1999). A homologous radioimmunoassay for the measurement of Urotensin II in the euryhaline flounder, Platichthys flesus. Gen. Comp. Endocrinol. 114, 249-256.

[25] Parmentier ,C., Taxi, J., Balment, R., Nicolas, G., and Calas, A. (2006). Caudal neurosecretory system of the zebrafish: ultrastructural organization and immunocytochemical detection of urotensins. Cell Tissue Res. 325, 111-24.

[26] Parmentier, C., Hameury, E., Lihrmann, I., Taxi, J., Hardin-Pouzet, H., Vaudry, H., Calas, A., and Tostivint, H. (2008). Comparative distribution of the mRNAs encoding urotensin I and urotensin II in zebrafish. Peptides 29, 820-829.

[27] Ribeiro, A., Monteiro, J.F., Certal, A.C., Cristovao, A.M., and Saude, L. (2017). Foxj1a is expressed in ependymal precursors, controls central canal position and is activated in new ependymal cells during regeneration in zebrafish. Open Biol. 7, pii: 170139.

[28] Laclef, C., Anselme, I., Besse, L., Catala, M., Palmyre, A., Baas, D., Paschaki, M., Pedraza, M., Métin, C., Durand, B., and Schneider-Maunoury, S. (2015). The role of primary cilia in corpus callosum formation is mediated by production of the Gli3 repressor. Hum. Mol. Genet. 24, 4997-5014.

[29] Mahuzier, A., Gaudé, H.M., Grampa, V., Anselme, I., Silbermann, F., Leroux-Berger, M., Delacour, D., Ezan, J., Montcouquiol, M., Saunier, S., Schneider-Maunoury, S., and Vesque, C. (2012). Dishevelled stabilization by the ciliopathy protein Rpgrip1l is essential for planar cell polarity. J. Cell Biol. 198, 927-40.

[30] Hellman, N.E., Liu, Y., Merkel, E., Austin, C., Le Corre, S., Beier, DR., Sun, Z., Sharma, N., Yoder, B.K., and Drummond, I.A. (2010). The zebrafish foxj1a transcription factor regulates cilia function in response to injury and epithelial stretch. Proc. Natl. Acad. Sci. U. S. A. $107,18499-504$. 
[31] Troutwine, B., Gontarz, P., Minowa, R., Monstad-Rios, A., Konjikusic, M.J. , Sepich, D.S. , Kwon, R.Y., Solnica-Krezel, L., and Gray, R.Y. bioRxiv 847301; doi: https://doi.org/10.1101/847301.

[32] Böhm, U.L., Prendergast, A., Djenoune, L., Nunes Figueiredo, S., Gomez, J., Stokes, C., Kaiser, S., Suster, M., Kawakami, K., Charpentier, M., Concordet, J.P., Rio, J.P., Del Bene, F., and Wyart, C. (2016). CSF-contacting neurons regulate locomotion by relaying mechanical stimuli to spinal circuits. Nat. Commun. 7, 10866.

[33] Djenoune, L., and Wyart, C. (2017). Light on a sensory interface linking the cerebrospinal fluid to motor circuits in vertebrates. J. Neurogenet. 31, 113-127.

[34] Viau, A., Bienaimé, F., Lukas, K., Todkar, A.P., Knoll, M., Yakulov, T.A., Hofherr, A., Kretz, O., Helmstädter, M., Reichardt, W., et al. (2018). Cilia-localized LKB1 regulates chemokine signaling, macrophage recruitment, and tissue homeostasis in the kidney. EMBO J. 37(15) pii: e98615.

[35] Singh, M., Garrison, J.E., Wang, K., and Sheffield, V.C. (2019). Absence of BBSome function leads to astrocyte reactivity in the brain. Mol. Brain 12, 48.

[36] Sun, S.L., and Liu, L.M. (2019). Urotensin II: an inflammatory cytokine. J Endocrinol. pii: JOE-18-0505.R2.

[37] Kimmel, C.B., Ballard, W.W., Kimmel, S.R., Ullmann, B., and Schilling, T.F. (1995). Stages of embryonic development of the zebrafish. Dev. Dyn. 203, 253-310.

[38] Haeussler, M., Schönig, K., Eckert, H., Eschstruth, A., Mianné, J., Renaud, J.B., Schneider-Maunoury, S., Shkumatava, A., Teboul, L., Kent, J., et al. (2016). Evaluation of offtarget and on-target scoring algorithms and integration into the guide RNA selection tool CRISPOR. Genome Biol. 17, 148.

[39] Mashal, R. D., Koontz, J., \& Sklar, J. (1995). Detection of mutations by cleavage of DNA heteroduplexes with bacteriophage resolvases. Nat. Genet. 9, 177-183.

[40] Stefanini, M., de Martino, C., and Zamboni, L. (1967). Fixation of Ejaculated Spermatozoa for Electron Microscopy. Nature 216, 173-174.

[41] Anselme, I., Laclef, C., Lanaud, M., Rüther, U., and Schneider-Maunoury. S. (2007). Defects in brain patterning and head morphogenesis in the mouse mutant Fused toes. Dev. Biol. 304, 208-20.

[42] Affaticati, P., Simion, M., De Job, E., Rivière, L., Hermel, J.-M., Machado, E., Joly, J.-S., and Jenett, A. (2017). zPACT: Tissue Clearing and Immunohistochemistry on Juvenile Zebrafish Brain. BIO-Protoc. 7.

[43] Schindelin, J., Arganda-Carreras, I., Frise, E., Kaynig, V., Longair, M., Pietzsch, T., Preibisch, S., Rueden, C., Saalfeld, S., Schmid, B. et al. (2012). Fiji: an open-source platform for biological-image analysis. Nat. Methods, 9(7), 676-682.

[44] Huang, D.W., Sherman, B.T., and Lempicki, R.A. (2009). Systematic and integrative analysis of large gene lists using DAVID Bioinformatics Resources. Nat. Protoc. 4, 44-57.

[45] Kwan, K.M., Fujimoto, E., Grabher, C., Mangum, B.D., Hardy, M.E., Campbell, D.S., Parant, J.M., Yost, H.J., Kanki, J.P., and Chien, C.B. (2007). The Tol2kit: a multisite gatewaybased construction kit for Tol2 transposon transgenesis constructs. Dev. Dyn. 236, 3088-99. 
bioRxiv preprint doi: https://doi. org/10.1101/2019.12.19.882258; this version posted December 19, 2019. The copyright holder for this preprint (which was not certified by peer review) is the author/funder, who has granted bioRxiv a license to display the preprint in perpetuity. It is made available under aCC-BY-NC-ND 4.0 International license.
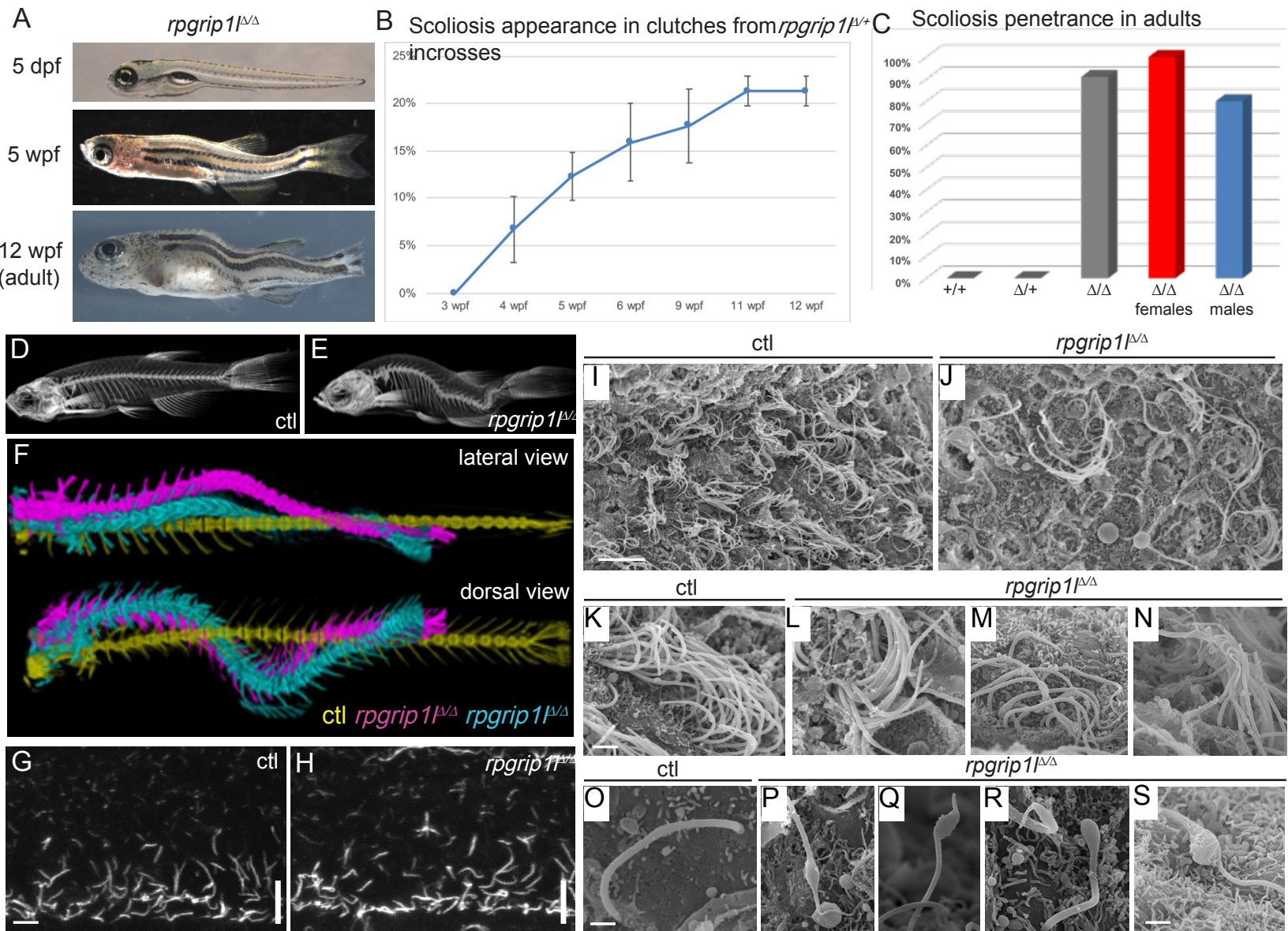

ctl
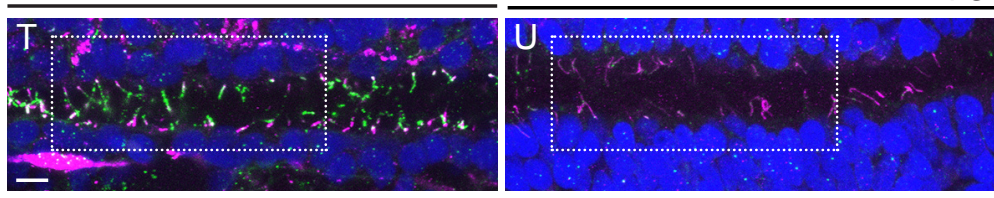

rpgrip $11^{1 / \Delta}$
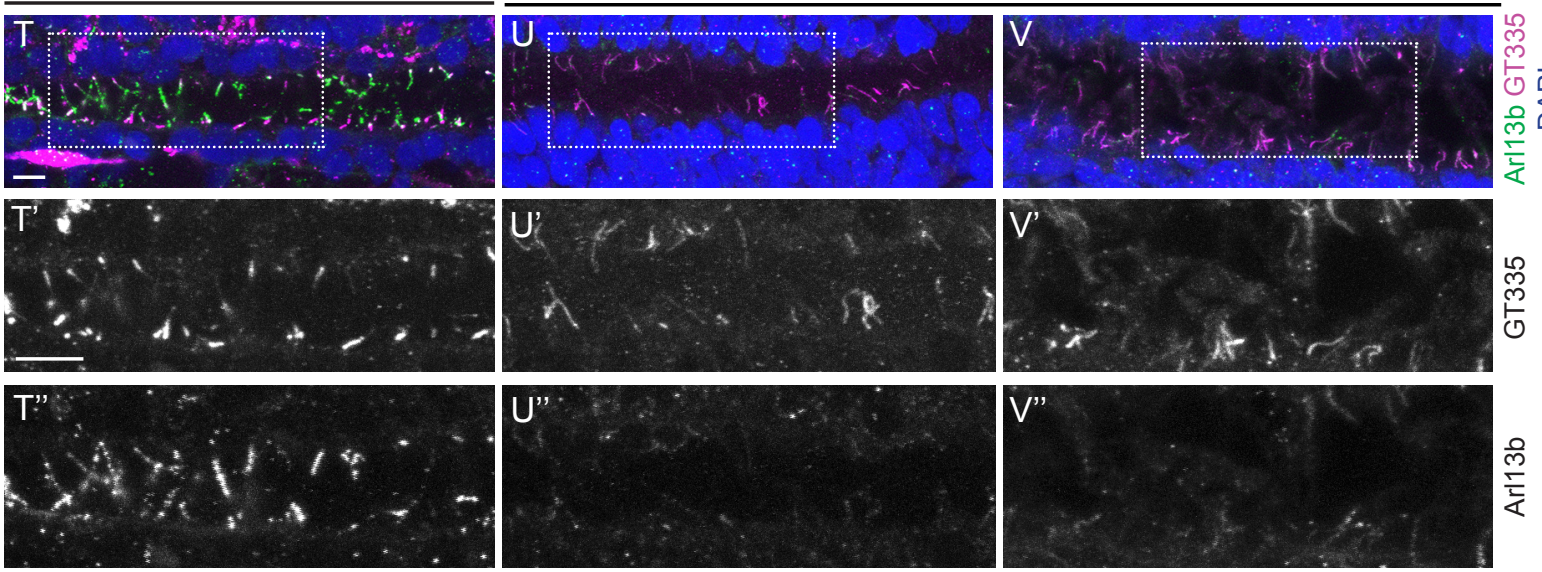

Vesque et al., Figure 1 


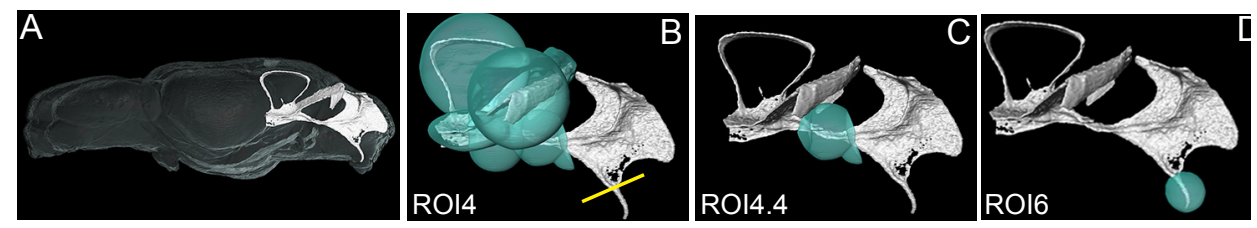

$\mathrm{E}$

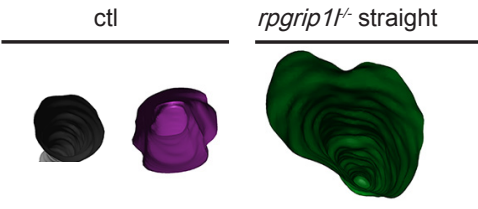

F Ventricular volume (arbitrary units)

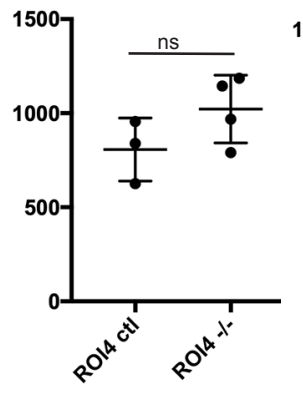

Control

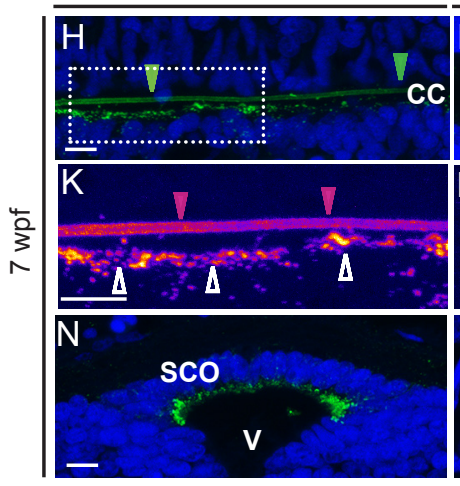

Control

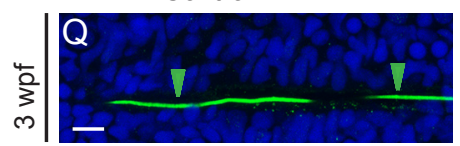

rpgrip 11 scoliotic

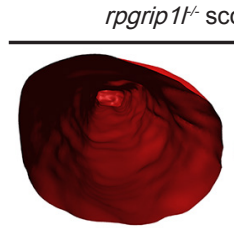

G Surface of ventricular section (arbitrary units)
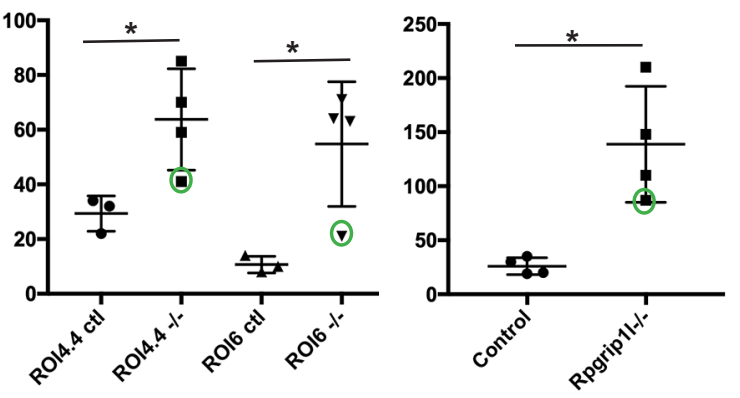

rpgrip $1 /^{-/-}$scoliotic

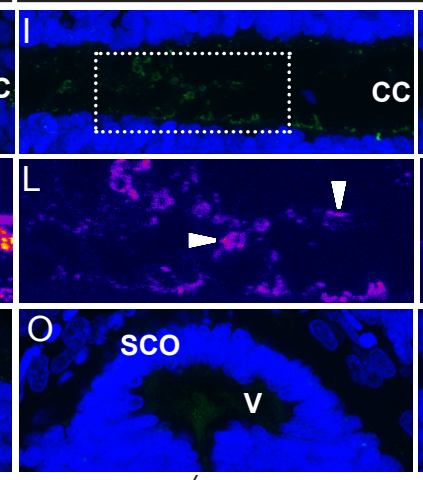

rpgrip $11^{-/-}$straight

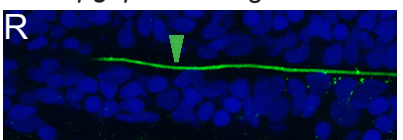

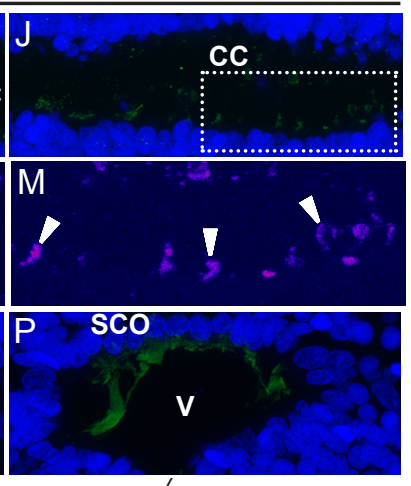

rpgrip $11^{-/-}$curved

Vesque et al., Figure 2

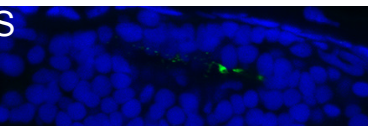


bioRxiv preprint doi: https://doi.org/10.1101/2019.12.19.882258; this version posted December 19, 2019. The copyright holder for this preprint (which was not certified by peer review) is the author/funder, who has granted bioRxiv a license to display the preprint in perpetuity. It is made available under aCC-BY-NC-ND 4.0 International license.

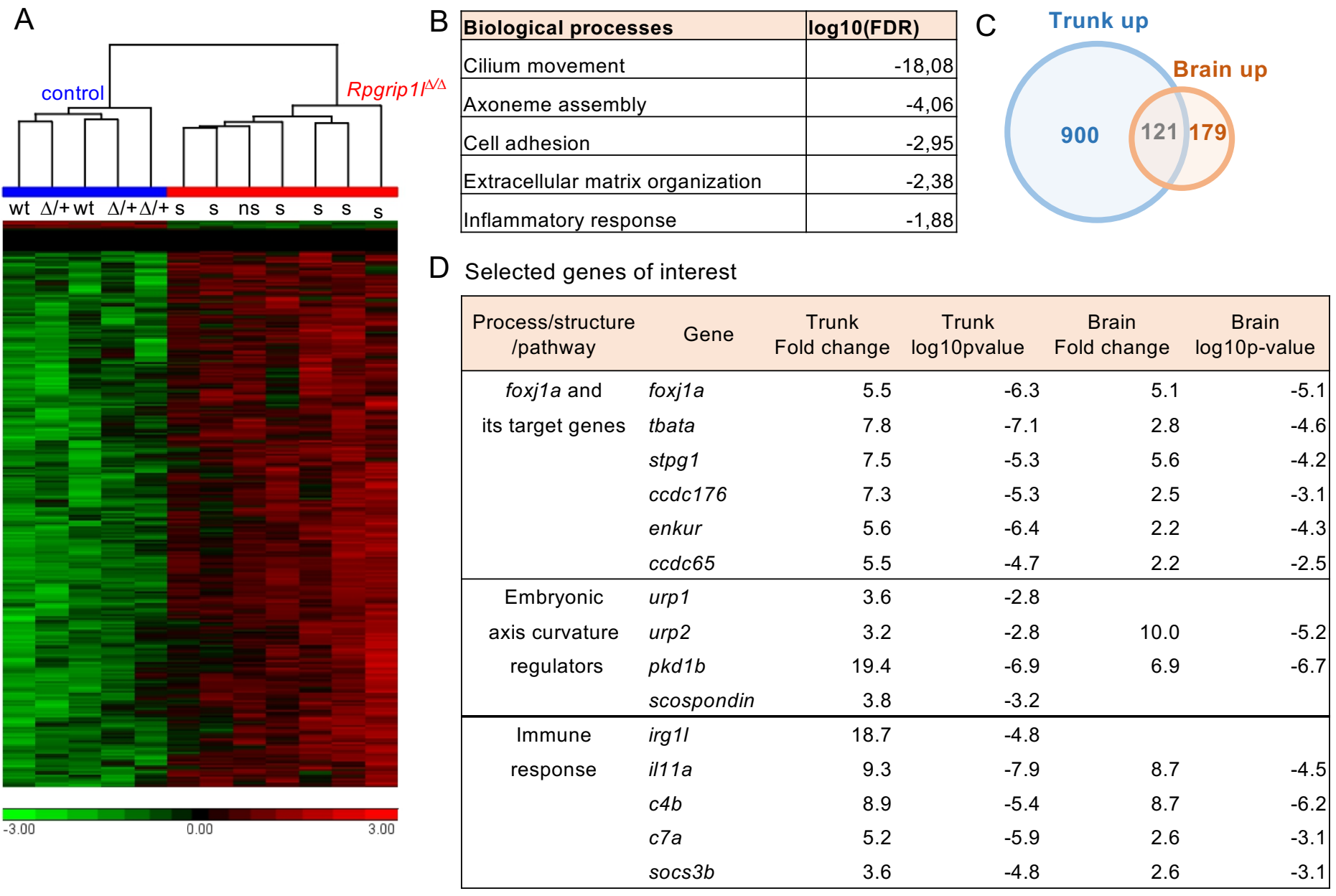

\section{Vesque et al., Figure 3}


bioRxiv preprint doi: https://doi.org/10.1101/2019.12 19.882258; this version posted December 19, 2019. The copyright holder for this preprint (which was not certified by peer review) is the author/funder, who has granted bioRxiv a license to display the preprint in perpetuity. It is made available under aCC-BY-NC-ND 4.0 International license.

A qPCR urp2 expression

Fold change

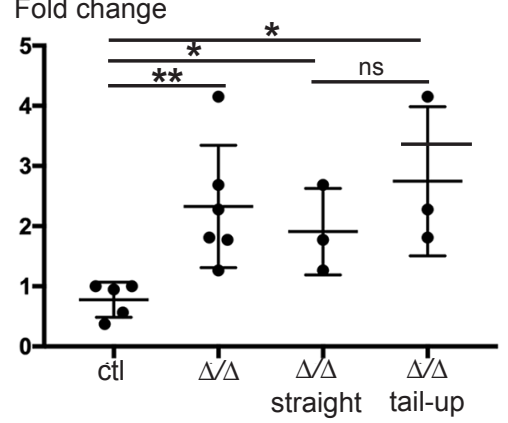

H Ratio of URP+ cells $\%$

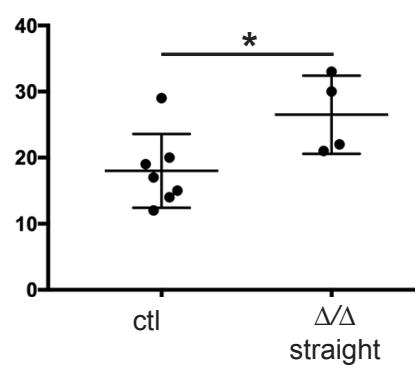

I Ratio of URP-strong cells
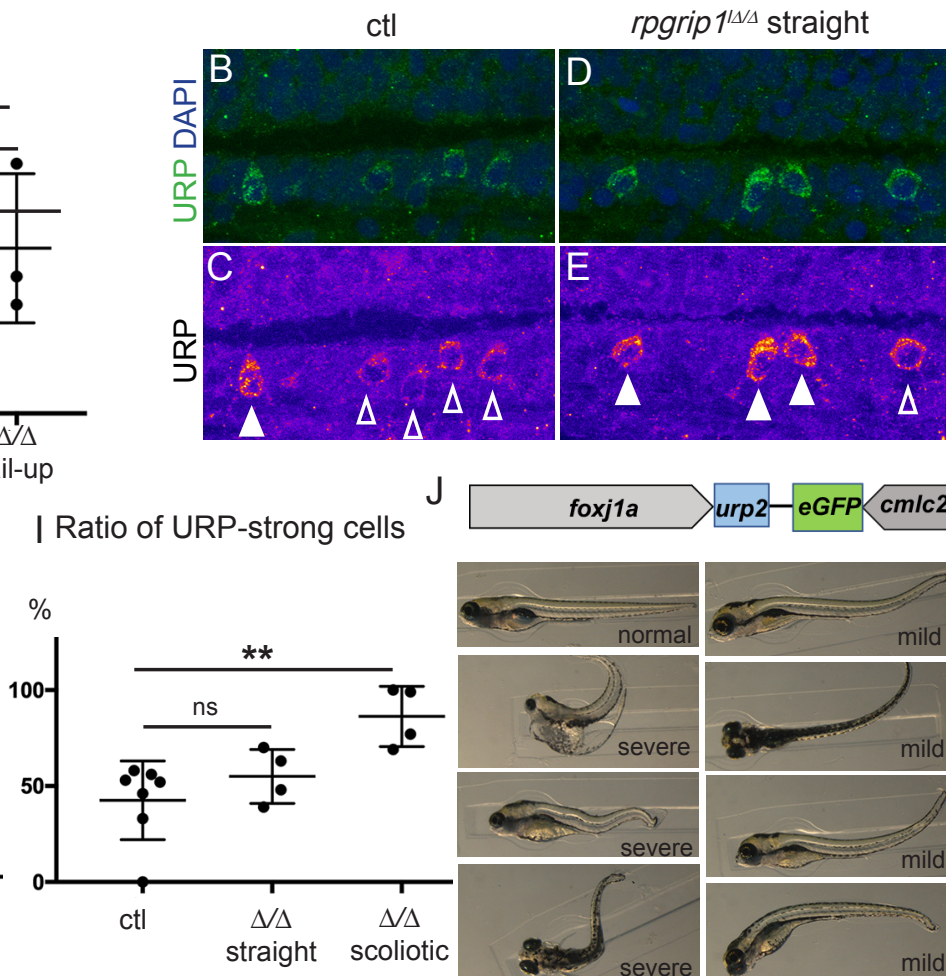

J
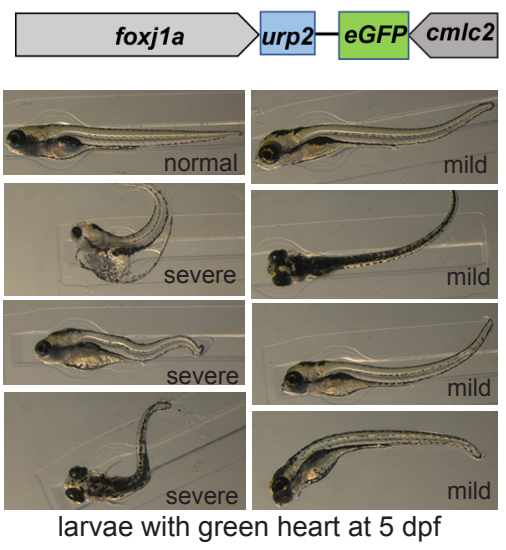

larvae with green heart at $5 \mathrm{dpf}$ rpgrip $1^{1 / / \Delta}$ curved
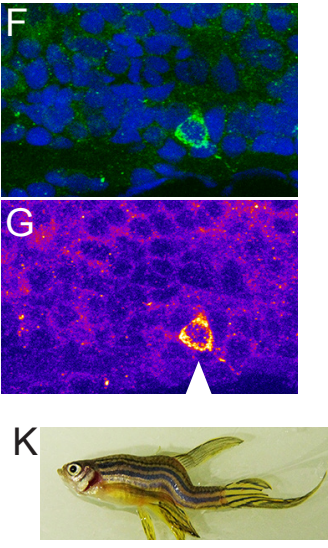

Ratio of scoliotic fish

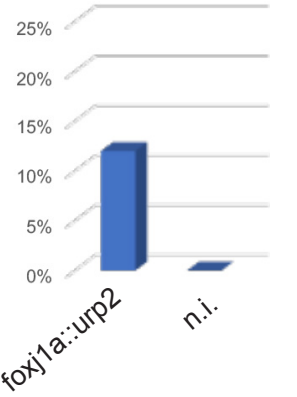

Vesque et al., Figure 4 